\title{
¿Qué subyace al ideal cosmopolita? Entre la perspectiva ilustrada y la globalización contemporánea
}

\author{
Griselda Gutiérrez Castañeda
}

$\mathrm{E}$

n los meses recientes, ante el estallido de la guerra contra Irak, las preocupaciones que de suyo vienen generando tanto el proceso de reacomodo unipolar del orden mundial, como la cadena de implicaciones que las tendencias globalizadoras desencadenan en la vida local, regional e internacional, fueron preocupaciones que alcanzaron el grado de alarma, al confrontarnos con escenarios en los que se ven desbordados todos aquellos recursos hasta ahora construidos para regular nuestras interdependencias, para normar la solución de los conflictos, inhibir el desencadenamiento de la violencia mediante las formas de pacificación institucionalizadas, a través de procedimientos de regulación, mediación y sanción.

La lectura que muchos hicimos de estos acontecimientos fue que la agresión de un Estado-potencia que hacía de la fuerza el recurso para afirmar su pretendido derecho, era la representación más cabal de lo que filosóficamente concebimos como estado de naturaleza, especialmente si a esa puesta en escena se suma, como en efecto ocurrió, el apelar a la polémica noción y pretensión de guerra justa, y el iniciar la acción bélica violentando el marco del derecho internacional, que además de anular, en los hechos, a la instancia de la ONU en tanto símbolo y garante del marco legal de las relaciones internacionales entre los Estados, se prescindió de su aprobación para el inicio de la guerra. Interpretar los acontecimientos como una fractura de ese horizonte jurídico, como un retroceso a la prevalencia de la razón de Estado, que hace "justos" los medios que se acomoden a los fines exclusivos del Estado-potencia, no parece un despropósito, más aún si atendemos a la gravedad de este proceder que se exacerba con los avances tecnológicos de la industria bélica y la flagrante violación de las mínimas reglas del ius in bello.

La radicalidad de estas circunstancias y riesgos produjo reacciones diversas, algunas permeadas por los valores humanistas ilustrados, fue mi caso, como pronunciamientos a favor de la revitalización de los cauces de discusión y 
negociación multilateral, de fortalecer el papel de la ONU y propugnar por su democratización, con lo cual se ratificaba la necesidad y deseabilidad de un orden político internacional, que sin menoscabo del conflicto, confirmase la posibilidad de construcción de un orden como tarea colectiva.

Los ecos de un orden cosmopolita confirmaban la filiación ilustrada de esta primera reacción, un análisis más frío con la distancia de los días, en el que se pueden aislar los efectos de las filias y actualizar otro valor ilustrado que es el de la crítica, habría de permitir desarticular la representación que nos hacemos de esas construcciones político institucionales, las expectativas y aspiraciones que simbolizamos y depositamos en ellas, la retórica de que esas instancias hacen uso y que bloquean una visión realista del papel que desempeñan, de sus posibilidades efectivas de intervención, y, como una cuestión nada menor, de las formas de prestidigitación que estas instancias internacionales, así como los Estados beligerantes, les hacen jugar a ciertas condensaciones simbólicas, valores, discursos e instituciones que hasta ahora se han concebido como las vías de una coexistencia civilizada.

Desarticular estos juegos y, sobre todo, contar con recursos teóricos apropiados para comprender los problemas y concebir soluciones posibles, me lleva a la consideración que si bien hemos de preservar el elemento crítico como gran legado ilustrado para nuestro horizonte de pensamiento contemporáneo, nada como aplicarlo a interpretar el repertorio categorial de las propuestas político modernas, que siguen siendo teórica y prácticamente nuestro marco de referencia, como es el caso de: el republicanismo que se concibió como el mecanismo para poner un coto a las cuotas de poder de la autoridad instituida que propugnaba por otra calidad de la relación de dominio entre gobernantes y gobernados; o el federalismo que reconocía la pluralidad y diversidad de actores sociales y políticos, que subyacen a las pretensiones de integración centralista de los Estados-nación; así como el cosmopolitismo, que buscaba la solución a los conflictos de poder entre naciones en la dimensión internacional.

El actual orden mundial en su tendencia globalizante, pero también unipolar, exige como nunca una revisión a fondo de lo que esos ideales nacionales, republicanos, federalistas, y por sobre todo cosmopolitas, pueden representar como marcos ordenadores en el contexto contemporáneo; desechar algunos o sobrevalorar los otros puede conllevar costos altísimos. La reflexión crítica filosófica nos plantea como tarea ineludible su desconstrucción, y en todo caso sopesar su resignificación para pensar el presente.

Se trata de una ardua tarea a la que muchos pensadores se vienen aplicando desde hace tiempo a la fecha, quienes atenazados por la urgencia de respuesta a problemas ingentes o al enfrentamiento con escenarios inéditos, les lleva en muchos casos a persistir en el recurso de los esquemas teóricos y 
conceptuales clásicos, soslayando la profundidad de las transformaciones estructurales y societales de los ordenamientos sociales y políticos contemporáneos, o en el extremo, negándole toda pertinencia y vigencia a esos repertorios interpretativos y conceptuales, al pronosticar la debacle de los marcos institucionales y normativos existentes.

Antes de definir una postura ante tales alternativas demos curso a un breve análisis del ideal cosmopolita ilustrado tal como se ha propuesto, que tiene una de sus más consistentes formulaciones en el pensamiento de Kant, lo cual cobra sentido no por meros afanes académicos, sino porque hoy día las propuestas para reforzar un pacifismo institucional descansan en principios cosmopolitas, como también en ellos se apoyan los globalistas occidentales a los que las fronteras territoriales y regulaciones estatales les estorban.

Es abigarrada la historia de esta noción y complejas las modalidades que ha cobrado, en su vertiente ilustrada, Kant construye un marco antropofilosófico desde el cual concibe a los seres humanos vinculados por el despliegue de sus facultades racionales y morales en un plano universal, que por lo demás cobra realidad en el proceso histórico mediante el despliegue activo de nuestras facultades, que nos hace artífices de una historia universal en tanto género humano, como miembros de una misma especie. Entiende que su realización no depende sólo de los individuos en cuanto tales, sino de la propia política, de los recursos y la actuación de los Estados como sujetos políticos.

El cosmopolitismo de Kant de profunda raigambre estoica, basado, por ende, en la convicción de la racionalidad que subyace a la necesidad del acontecer y a la inteligibilidad que proporciona a los hombres para guiar su acción y colegir normas que la regulen, mantiene una distancia con la acepción clásica antigua por cuanto está lejos de negar las divisiones territoriales y políticas; como representante de los ideales modernos concibe las nociones de patria, nación, Estado, como el marco que condensa los grandes objetivos políticos del mundo moderno que son, en palabras de Charles Taylor, el bienestar, los derechos, y el autogobierno, ${ }^{1}$ los cuales sólo son factibles en el marco de la nación. Kant no es ajeno al espíritu de los humanistas que en su momento recuperan los ideales cosmopolitas como la forma de resistencia a las intolerancias religiosas y a las formas exacerbadas de afirmación de los regímenes absolutistas, como tampoco lo es a los ideales pacifistas de muchos intelectuales modernos ante la deriva de las guerras de religión o las luchas por la hegemonía político económica de los Estados europeos. Como un cabal ilustrado nunca habría adscrito un cosmopolitismo sustentado en el universalismo religioso a la manera de Schlegel, que contrapone la comunidad de

${ }^{1}$ Charles Taylor, Acercar las soledades: federalismo y nacionalismos en Canadá. San Sebastián, Tercera Prensa, 1999, p. 42. 
moral y religión al imperio de la avidez y el dominio napoleónico, y como un cabal liberal nunca dudó del carácter plausible propio a su época, de las bondades del Estado-nación -y en su caso, acentuado como una aspiración no cumplida en el contexto alemán de su época-, la soberanía y centralismo del Estado-nación se conciben como la garantía de estabilidad y paz que las intervenciones imperialistas de otros Estados le escamotean, y al interior favorece la posibilidad de crear condiciones que permitan y promuevan el desarrollo de los integrantes de la comunidad política, vale decir, ejerciendo sus derechos, desplegando potencialidades, regulando autónoma y dignamente sus relaciones sociales, políticas e interpersonales.

Si bien la línea racionalista y moralizante tiene un peso indiscutible en los planteamientos de Kant, hay una veta realista que se hace presente y le lleva a reconocer la fuerza de los intereses y conflictos, la mera existencia de Estados independientes y a la vez vecinos, es condición de suyo para hostilidades y confrontaciones, los intereses expansionistas, los afanes de dominio sobre otros, y elánimo beligerante, son realidades persistentes. No deja de asombrarle que las pretensiones de los Estados sean el procurarse lo que juzgan su derecho mediante la guerra, en la que cada uno aparece como juez de sus asuntos, y para los que la victoria determina lo que es justo o no lo es, la radicalidad de los riesgos puede llevarles a tratados de paz, que como armisticios, según su decir, no son una verdadera solución a la situación de guerra en general. Establecer regulaciones de este tipo “...sería [por así llamarlo] un derecho que determinaría qué es justo según máximas unilaterales del poder, y no según leyes exteriores... de validez universal", ${ }^{2}$ tal situación equivaldría a una libertad salvaje en la que los Estados optan por la posibilidad de la lucha antes que la sumisión a regulaciones externas, incluso legales, por considerar que les resta poderío y soberanía. En opinión de Kant, si éste fuese el equivalente de un derecho de gentes, en realidad sería reducirlo a un derecho para la guerra, por cuyo conducto lo único que se puede alcanzar es la paz de los sepulcros, para salir de la situación sin ley y el riesgo de la guerra, los Estados no tienen otro medio "...que el de consentir leyes públicas coactivas...", 3 que le reconozca un estatus jurídico a cada Estado, que proceda de algún contrato entre las partes, y que sea una suerte de asociación libre, cuyo único propósito es mantener la paz. Esta modalidad es provisional, una etapa, dentro de un proceso de mayor alcance guiado por un ideal cosmopolita.

En este punto cabe detenerse y considerar los elementos clave que integran su propuesta: Kant asume como una premisa irrebatible la existencia y la necesaria preservación de la soberanía de los Estados; el problema son los

${ }^{2}$ Immanuel Kant, La paz perpetua. Madrid, Tecnos, 1985, p. 25.

${ }^{3}$ Idem. 
términos de la coexistencia, que si se ha de encaminar hacia la paz requiere acuerdos, ¿cuál es entonces la forma de unión y el tipo de acuerdos en que deban de sustentarse, tal que no altere esa premisa? Su propuesta, como sabemos, es la de una relación federada.

Parece una alternativa plausible que contempla una salida a problemas fundamentales, pero que descansa en procedimientos de partida que no se someten a discusión

Los pueblos pueden considerarse, en cuanto Estados, como individuos que en su estado de naturaleza (es decir independientes de leyes externas) se perjudican unos a otros por su mera coexistencia y cada uno, en aras de su seguridad, puede y debe exigir del otro que entre con él en una Constitución semejante a la Constitución civil, en la que se pueda garantizar a cada uno su derecho. Esto sería una federación de pueblos que, sin embargo no debería ser un Estado de pueblos [...] muchos pueblos en un Estado vendrían a convertirse en un solo pueblo, lo cual contradice la hipótesis $[\ldots]^{4}$

En efecto, Kant no pretende que los pueblos pierdan sus atribuciones, para lo cual la forma no puede ser más que una relación federada que preserve la libertad y estatus de cada Estado y pueblo, una relación abierta que conserve el pluralismo y les una o vincule en aquello que es necesario, se trataría por tanto de:

Una federación de tipo especial a la que se puede llamar la federación de la paz (foedus pacificum) que se distinguirá del pacto de paz (pactum pacis) en que éste buscaría terminar con todas las guerras para siempre. Esta federación no se propone recabar ningún poder del Estado sino garantizar solamente la libertad de un Estado para sí mismo y, simultáneamente, la de otros Estados federados, sin que éstos deban por esta razón (como los hombres en estado de naturaleza) someterse a leyes públicas y a su coacción. Es posible representarse la posibilidad de llevar a cabo esta idea (realidad objetiva) de la federación, que debe extenderse paulatinamente a todos los Estados, conduciendo así a la paz perpetua. ${ }^{5}$

Cuando Kant aplica el procedimiento de analogía interna se puede observar que por un lado es consciente de que le puede rendir amplio provecho en

${ }^{4}$ Ibid., p. 21.

${ }^{5}$ Ibid., p. 24. 
vías de ofrecer una alternativa para la paz duradera, pero por otro tiene claridad de las dificultades que puede depararle; en efecto, establecer una analogía entre individuos y Estados tiene el riesgo de que lo que vale para los primeros puede generar inconsistencias y efectos no deseados para los segundos. Como la teoría del pacto establece, los individuos al pactar en aras de fundar un Estado civil, han de aceptar un poder superior al que le atribuyen la facultad de mediar entre las partes y con capacidad coercitiva para preservar el orden, lo cual es consistente con la integración del Estado.

Pero aplicar esta misma lógica a la relación o pacto entre Estados, plantea la dificultad de aceptar un poder superior por encima de las partes pactantes que pudiese tener atribuciones coercitivas poniendo en entredicho la soberanía estatal. Kant que por supuesto repara en ello, declara que ese poder no puede ser coercitivo, la soberanía queda a buen resguardo al pensar en una federación libre. Sin embargo, y pese a su insistencia en que se trata de una federación libre de sociedades civiles, al considerar que ningún Estado puede basar la confianza en su derecho en su relación con otros Estados, si no es consintiendo en leyes públicas coactivas, se verá en problemas, aun cuando a continuación introduzca la precisión de que tal unión responde a una forma republicana expresada en la idea positiva de un Estado mundial, en tanto república mundial, en el entendido de que se trata de un derecho internacional comunitariamente pactado, para el que no están a debate los derechos de quienes adscriben tal acuerdo, el estatus de igualdad, el consentimiento libre y la corresponsabilidad.

Pero proponer una forma republicana no sólo significa cumplir con estas condiciones, también implica asumir que la dependencia a una legislación común les coloca en situación de súbditos, lo que se consolida con la institucionalización del principio de la división de poderes, ejecutivo, legislativo, judicial, por lo cual lo que se establece no es sólo un pactum societatis, sino además, un pactum subjectionis. Ciertamente, Kant es meticuloso y al proponer ese Estado cosmopolita, intentará cerrar el paso a la legitimidad que cualquier Estado poderoso y despótico se pretendiese arrogar, o a cualquier sucedáneo negativo de su propuesta a manera de federación permanente en continua expansión. La dificultad es que ni su confianza racionalista en el poder de las leyes tiene la fuerza bastante para contrarrestar las pretensiones hegemónicas de los Estados, ni sus cuidadosos argumentos para delimitar el sentido republicano de su propuesta en la federación libre de Estados impedirá lecturas, sino que más bien las propicia para concebir el cosmopolitismo hoy día como la antítesis de su propuesta.

Antes de entrar al análisis de las versiones contemporáneas, es fundamental detenernos un momento más en otro de los ejes del cosmopolitismo visualizado por Kant, que no se concreta solamente al eje relativo a la construcción 
de la paz, me refiero a los intercambios regulares entre los Estados, a las relaciones económicas que requieren situaciones estables, si bien pueden ser el pivote que desencadene las hostilidades, cuestión que no le pasa inadvertida al autor. Existe una forma de unión entre los pueblos dictada por la sana razón que permite preservar la vida estableciendo acuerdos para construir la paz, pero hay otra que sin duda tiene una presencia indiscutible, la que se guía por el propio provecho, y el provecho recíproco

Se trata del espíritu comercial que no puede coexistir con la guerra y que, antes o después, se apodera de todos los pueblos. Como el poder del dinero es en realidad, el más fiel de todos los poderes (medio) subordinados al poder del Estado, los Estados se ven obligados a fomentar la paz (por supuesto, no por impulsos de la moralidad) y a evitar la guerra con negociaciones. ${ }^{6}$

Aunque en otro de sus ensayos se propone demostrar que el derecho internacional para construir la paz se puede defender por razones filantrópicas, que le dan un respaldo a su cosmopolitismo ilustrado, al ocuparse de la otra modalidad de relación entre los Estados, Kant está claro que no son motivaciones filantrópicas las que llevan a evitar la guerra, a procurar la paz y con ello el éxito de los negocios, son intereses sin más los que exigen regulaciones que normen las negociaciones, pero aun allí pese a no ser asuntos filantrópicos, son cuestiones de derecho, así veremos que en este tenor denomina como derecho de hospitalidad el que cualquier extranjero tiene de no ser tratado hostilmente al visitar otro territorio, aun intentar un tráfico con los habitantes del lugar es su derecho, pero no lo es trastocar la visita en conquista. A su entender, se puede en el campo de los negocios establecer relaciones pacíficas, pero además legales y públicas.

La pertinencia de estas observaciones cobra mayor relevancia por cuanto el autor atiende a un fenómeno que tiene un gran peso en su momento, las empresas imperialistas de los Estados-nación consolidados, y que desde luego sería una tendencia que iría a más, dándole una gran actualidad a sus reflexiones en los tiempos que vivimos

Como se ha avanzado tanto en el establecimiento de una comunidad (más o menos estrecha) entre los pueblos de la tierra, que la violación del derecho en un punto de la tierra repercute en todos los demás, la idea de un derecho cosmopolita no resulta una representación ni fan-

${ }^{6}$ Ibid., p. 40. 
tástica ni extravagante, sino que completa el código no escrito del derecho político y del derecho de gentes, en un derecho político de la humanidad, siendo un complemento de la paz perpetua $[\ldots]^{7}$

Como se puede apreciar, su interpretación del cosmopolitismo ni en el plano político ni en el económico se identifica o adscribe a la idea de restarle estatus y derechos a los Estados soberanos.

Veamos ahora la cuestión desde otro ángulo, si bien el gran legado de Kant es su idea de la unidad espiritual del género humano, su relevancia es menor si de entender la política se trata, cobra en cambio más significado el papel modélico de sus tesis, que no siempre repercuten para bien en las discusiones contemporáneas.

Retomando el punto anterior, destaca la difícil coexistencia de la defensa que hace Kant del derecho de soberanía de los Estados con la tesis de un Estado mundial como garantía de una coexistencia pacífica y justa, de alguna forma estaría buscando compaginar dos modelos de relaciones internacionales contrapuestos, los que Danilo Zolo denomina el modelo Westfalia y el modelo cosmopolita de la Santa Alianza, el primero que consagra el derecho de todo Estado nacional a ejercer el monopolio legítimo del poder dentro de sus fronteras y a afirmar su soberanía respecto a cualquier autoridad externa, modelo que para posibilitar la paz entre los Estados no puede más que apelar a la construcción de equilibrios entre las naciones, ${ }^{8}$ en tanto que el segundo, tal como lo caracteriza Zolo, es "...la formación de una entidad política con aspiraciones de ser universal, pacífica, jerárquica, monocéntrica o en cualquier caso centrada en Occidente".

Desde luego que hay una serie de diferencias en esta caracterización respecto a la propuesta de Kant que hemos venido analizando, pero la persistente reacción a aglutinar a los Estados en forma internacional para contender con los riesgos de la guerra y la inestabilidad, es una propuesta cuyo espíritu está presente en Kant, como lo estuvo en la Santa Alianza que las potencias vencedoras crearon tras derrotar a Napoleón (1814-1824), y que como Hegel

${ }^{7}$ Ibid., p. 30.

${ }^{8}$ Es un modelo que surge a partir del acuerdo fundacional entre la "familia de naciones" en tiempos de la Paz de Westfalia, con el que se puso fin a la Guerra de los Treinta Años, en 1648. Es el momento de afirmación de los Estados soberanos frente a las pretensiones de la Iglesia y del Imperio. Un modelo que se universaliza a fines del siglo XIX, si bien tuvo su primer descalabro con las guerras napoleónicas de principios del mismo siglo, desbaratando el equilibrio entre los Estados europeos.

${ }^{9}$ Danilo Zolo, Cosmópolis. Perspectiva y riesgos de un gobierno mundial. Barcelona, Paidós, 2000, p. 30. 
ironiza parece ser un modelo construido por Kant para la Santa Alianza, y una reacción que se repite en los fundamentos de todas las organizaciones internacionales de entonces a la fecha, como la Sociedad de Naciones, la Organización de las Naciones Unidas, etcétera.

Generalmente, todas han sido iniciativas que han establecido el principio de una federación internacional destinadas a promover la paz, pero en todas pareciera que el principio federal ha sucumbido bajo el control real de las principales potencias que han fundado tales organismos.

El modelo cosmopolita de la Santa Alianza responde al intento de asegurar una paz mundial estable, mediante el recurso de formas de organización permanentes capaces de responder ante situaciones de conflictos bélicos, y que salven el riesgo y la improbabilidad de que esto se pueda lograr mediante el principio del equilibrio entre los Estados, son formas que pese a su retórica, presentan acusados rasgos de instituciones centralizadas, jerárquicas y que incluyen algún tipo de poder coercitivo.

El dilema que enfrenta Kant tiene relevancia por su carácter paradigmático, en primer término, al no poder dejar de reconocer que los Estados nacionales tenían la necesidad de afianzar el centralismo para consolidarse como nación hacia dentro y para afirmarse como Estado nación hacia fuera, necesidad que Kant matizará con su propuesta republicana; lo cual no obsta, para que la finalidad instrumental que se les juega a los Estados marque las pautas. En segundo término, está el plano de las interrelaciones, el discurso ilustrado destaca una veta idealizada que explica las bondades de que las relaciones entre los Estados sean de forma federada, tales bondades son la búsqueda de la libertad y la consolidación de sociedades democráticas, republicanas conforme al espíritu kantiano, y al mismo tiempo, un sistema federal o república mundial que concibe esta vía en términos sociales bajo la pretensión de que puede haber intereses comunes, que sin ocluir los intereses nacionales puedan trascenderlos. Éstas, como dirá Riker, ${ }^{10}$ son falacias, que más allá de su función ideológica impiden enfrentar de manera directa los intereses nacionales en juego y el cauce que se deja abierto al centralismo y sus efectos, por cuanto las relaciones son asimétricas y la posibilidad de una unión armónica, en donde las partes intervienen de forma integrada y equilibrada, así como las posibilidades de conciliación de intereses y de decisiones consensuadas es improbable. Una unión federada sólo es tal si el grado de asimetría no rebasa la funcionalidad del sistema, de manera que en los acuerdos y en la toma de decisiones dentro de tales organismos no se pase a ocupar el puesto de meros

${ }^{10}$ W. H. Riker, Federalism: Origin, Operation, Significance. Boston, Little Brown, 1964, pp. 14-16. Apud Miquel Caminal, El federalismo pluralista. Del federalismo nacional al federalismo plurinacional. Barcelona, Paidós, 2002, p. 97. 
comparsas, como en efecto ocurre con muchos de los integrantes de tales formas de unión.

Ciertamente, cuando Kant plantea la relación federada de los Estados, está pensando en la creación de una unión en la que todas las partes tienen capacidad de decisión, en la que las decisiones han de tomarse en forma horizontal y concurrente que, por cierto, es la forma característica de las confederaciones, proponer en cambio una federación conlleva formas de decisión vertical y por mayoría, lo cual se puede constatar en el modelo al que responden organismos internacionales como la oNU, en lo que hace a la verticalidad dada la capacidad decisional de las potencias fundadoras, en la que la mayoría la imponen o construyen las mismas potencias, mediante presiones a los otros países miembros.

Vale la pena detenerse en algunos aspectos que caracterizan a la organización de la ONU porque retratan de manera fiel la verdadera correlación de intereses y fuerzas que inciden en el orden mundial, y desde luego porque nos sirve de referente para calibrar los sentidos e implicaciones del cosmopolitismo. En su integración, más allá de las declaraciones y cartas de intención como que es un proyecto cosmopolita de paz duradera, está contemplado que dicha tarea descanse en un poder fuertemente centralizado, su organización centralizada y jerárquica está supeditada a la voluntad de las grandes potencias, lo cual les permite un control coercitivo de las disputas internacionales, que en los hechos ejercen por su propio poderío, pero que además cuenta con el aval de jure de la organización misma. Esta situación está sustentada en mecanismos como votos de calidad, poder de veto y la ausencia de reglas que impongan la abstención de cualquiera de las potencias en tanto miembros del Consejo de Seguridad, cuando estén directamente implicadas en los conflictos.

Ésta es la verdadera plasmación de su cosmopolitismo, pensar que esta situación se pudiera ver atemperada por el elemento federalista, es sólo una vana ilusión, curiosamente sólo se aplica cuando de recomendar el uso de la fuerza militar en forma colectiva se trata, la recomendación de Kant de que la federación sólo puede estar integrada por Estados republicanos, no impide que inescrupulosamente se acepte la adhesión de Estados que están muy lejos de respetar los derechos básicos de sus ciudadanos, la posibilidad de intervención coercitiva, armada, se aplica conforme a principios francamente preocupantes, que en una suerte de analogía interna hobbesiana, pretende que el orden internacional sólo se podrá garantizar si los Estados renuncian a ejercer justicia por su propia cuenta y aceptan el monopolio del uso de la fuerza militar por parte del Consejo de Seguridad, que por interpósita persona resultan ser los ejércitos de los propios Estados miembros, por todo ello, el estatus de los miembros de la federación queda en entredicho. Al mismo 
tiempo una organización concebida para la paz parece carecer de un modelo teórico y de mecanismo que permitan inhibir y controlar el conflicto, tan es así que ni siquiera existen regulaciones para que los países miembros tengan prohibido suministrar y negociar con armamento con las fuerzas beligerantes.

Estos datos mínimos son por sí mismos preocupantes, cuando se trata de una organización que se concibió como promotora de la paz, de carácter cosmopolita y democrático, defensora de los más altos valores y derechos, lo es aún más si atendemos a la escasa eficacia en su mediación e inhibición de las guerras y la construcción de la paz, pero a la ineficacia se une el peligro que representa concentrar todas las expectativas en una institución de tales características, y que al mismo tiempo carece de los recursos para sustraerse a los juegos aviesos a que se le somete, particularmente si atendemos al desempeño hegemónico que una potencia como Estados Unidos viene desplegando al no tener el contrapeso de la bipolaridad, el cual cobra toda su contundencia en el proceso que va de la Guerra del Golfo, o Tormenta del Desierto, a la actual agresión contra Irak, como expresión de la guerra defensiva dentro de un plan global de seguridad .

Tan inquietante es que se le haya colocado en posición de dar el aval para la incursión de la Guerra del Golfo, como que se le haya arrinconado y anulado ante la inminencia de la agresión contra Irak, éstas son desde luego las dificultades mayores, pero resulta además profundamente inquietante la reacción que tales acontecimientos han generado entre políticos, analistas y teóricos.

El aval que la ONU dio a la Guerra del Golfo ha llevado a muchos interesados a pugnar por el fortalecimiento del Consejo de Seguridad, por su parte, a los críticos de este proceder les inspira la causa por la democratización y la reforma del organismo, en el primer caso se podría hablar de un cosmopolitismo autocrático, como lo denomina Zolo, en el segundo un cosmopolitismo democrático, en el entendido de que pueda ser capaz de contender con los grandes desafíos de las guerras, pero también con los riesgos que genera y/o agudiza la globalización en el ámbito tecnológico, financiero, ecológico y demográfico, sumados a la explosión y profundización de los particularismos étnicos y nacionales.

Podríamos decir que resulta por lo menos ingenuo que se pueda contender con estos problemas, al margen de las pautas que marcan los intereses de las grandes potencias, y que cualquier intento de democratización al interior del organismo pueda atenuar el peso de esos Estados miembros.

No puede menos que generar perplejidad que incluso teóricos como Bobbio persistan en el modelo de un Estado mundial al suponer que la única manera de resolver la anarquía internacional y la guerra sea a través de la construcción de un Estado ordenado y pacífico, para lo cual no duda que los Estados 
individuales tendrían que suscribir, conforme a la analogía interna, un pacto societatis, así como un pacto subjectionis; piensa que mientras los Estados integrantes sigan haciendo valer su derecho de soberanía, esta organización no alcanzará una verdadera democratización. En esta línea, cuando de pronunciarse sobre la Guerra del Golfo se trató, Bobbio, basándose en la consistencia teórica de su concepción pacifista institucional, hubo de considerarla una guerra justa, por cuanto asume que la concentración del poder militar en manos de una autoridad suprema internacional es la única manera de construir la seguridad y la paz internacional, y porque la ONU representa un avance significativo en ese sentido.

Tal pareciera que la inevitabilidad de esa guerra hubiese estado fuera de discusión, que la concentración del poder y el derecho de coerción fuesen las mejores vías para procurar la paz y no más bien lo contrario, y que se pudiese soslayar sin más el carácter no democrático de la organización, su carácter centralista y jerárquico, y dar por bueno el discurso de que representa y defiende causas comunes y valores universales, como los derechos humanos.

Es indudable que los Estados nacionales enfrentan retos para los que sus estructuras y principios no alcanzan, que estas últimas han desencadenado realidades polémicas, pero valdría la pena preguntarnos si el modelo westfaliano que pretende equilibrios y acuerdos coordinados entre Estados independientes y soberanos no es preferible y el último reducto para protegernos del poder dictatorial de potencias con máscara cosmopolita, de organismos que para construir la paz legitiman la guerra, que se presentan como portadores de universalidades valiosas cosmopolitas, y de un cosmopolitismo global que nos ofrece ser ciudadanos del mundo mediante condiciones homogeneizadoras económicas, políticas y culturales que nos asimilan pero no nos integran.

Queda abierta la pregunta: ęes el cosmopolitismo la vía para la paz y para la democratización en las relaciones internacionales? 